\title{
Study of the Distribution of Air Temperature in a Greenhouse Heated By Air to Air Heat Pump
}

\author{
Agris Auce \\ Institute of Chemical Physics \\ University of Latvia \\ Riga, Latvia \\ a@aa.lv \\ Semjons Ivanovs \\ Ulbroka Research Center \\ University of Life Sciences and \\ Technologies \\ Jelgava, Latvia \\ semjons.ivanovs@llu.lv
}

\author{
Aivars Jermuss \\ Institute of Agronomy \\ University of Life Sciences and \\ Technologies \\ Jelgava, Latvia \\ aivars.jermuss@llu.lv
}

\author{
Ugis Grinbergs \\ Institute of Mathematics and \\ Computer Science \\ University of Latvia \\ Riga, Latvia \\ ugis@adsl.lv
}

\author{
Adolfs Rucins \\ Ulbroka Research Center \\ University of Life Sciences and \\ Technologies \\ Jelgava, Latvia \\ adolfs.rucins@llu.lv
}

Abstract - The temperature distribution inside the experimental greenhouse heated by air to air heat pumps and its impact on the growth and productivity of tomato plants were studied. Experimental greenhouse located at SIA Rītausma facility in South-East Latvia.

Two commercially available regular air to air heat-pumps with a combined heat power of $10 \mathrm{~kW}$ were used. To measure the temperature distribution, 18 temperature sensors with solar radiation shields at different heights and positions among the plants were installed. Additional 4 temperature sensors were used to measure the air flow temperature at the heating elements. Reference air temperature was measured at an industrial production facility heated by a common gas heating system.

Temperature was found to be homogenous within $1^{\circ} \mathrm{C}$. Observed temperatures were up to $4^{\circ} \mathrm{C}$ lower than set on the control unit of the heat pump. This discrepancy was compensated by higher set values for the controlling unit. As research showed the temperature stability was better than at the water-heated industrial facility at time slots when the sun was suddenly cleared from clouds.

The cooling of the experimental greenhouse by air conditioning during summer time was rather challenging for the tomato plants and productivity. $23 \%$ of plant stems died until the end of the season and the yield was $50 \%$ lower than in the reference greenhouse. The energy efficiency compared to the industrial facility was approx. 8 times better and the estimated $\mathrm{CO}_{2}$ emissions were 8-16 times smaller compared to gas heating. There were no increases of heating costs determined.
Further studies are needed to optimize the heating parameters and reach the desired greenhouse productivity.

Keywords - air temperature, air to air heat pump, greenhouse heating.

\section{INTRODUCTION}

Greenhouse crop production is an important part of agricultural production, especially for northern countries with cold climate [1]. Air conditioning systems in the greenhouse can provide a suitable environmental condition for agricultural production. Greenhouse crop production in cold regions requires a lot of energy that results in the emission of a significant amount of greenhouse gas $\left(\mathrm{CO}_{2}\right)$ and other air pollutants such as NOx into the atmosphere [2]. A large amount of fossil fuels is used for greenhouse heating in industrial farming systems. The burning of coal, natural gas, and oil for electricity and heat is the largest single source of global greenhouse gas emissions and accounts for $25 \%$ of global emissions by the economic sector [3]. In the past, heat pumps have not been used widely because of their low coefficient of performance (COP) and high cost of installation [4]. With the rise of energy costs and technological advancements, heat pumps are now being reconsidered as an alternative heating system [5]. The efficiency of heat pumps in subarctic areas are stated in [6]. 
$\mathrm{CO}_{2}$ emissions can be significantly reduced by the integration of renewable energy in industrial applications [7]. The coefficient of performance (COP) of heat pump, especially of air-source heat pumps is decreasing at lower temperatures [8]. A reduction in the energy required for greenhouse heating and cooling by regulation of heating and cooling facilities for an optimum growing environment during the plant growth stage was reported by Rubanga et al. 2019 [9]. Air-to-air heat pumps require little investment compared to other types of heat pumps and other heating systems. However, it is not yet clear whether heating by direct air flow from air-to-air results in an acceptable temperature distribution within a densely packed greenhouse used for tomato growing. Therefore, the performance and $\mathrm{CO}_{2}$ emissions of air-to air heat pumps should be studied in a real location with real production plants. The aim of this research is to investigate the spatial and temporal distribution of air temperature in an industrial tomato greenhouse heated by air to air heat pump in south eastern Latvia.

\section{MATERIALS AND METHODS}

The air heating systems were studied in an experimental greenhouse $34 \mathrm{~m}^{2}(\mathrm{~B}=4.15, \mathrm{~L}=8.30$, $\mathrm{H}=3.40+0.7 \mathrm{~m}$ ceiling) separated from the main industrial facility at its north east corner.

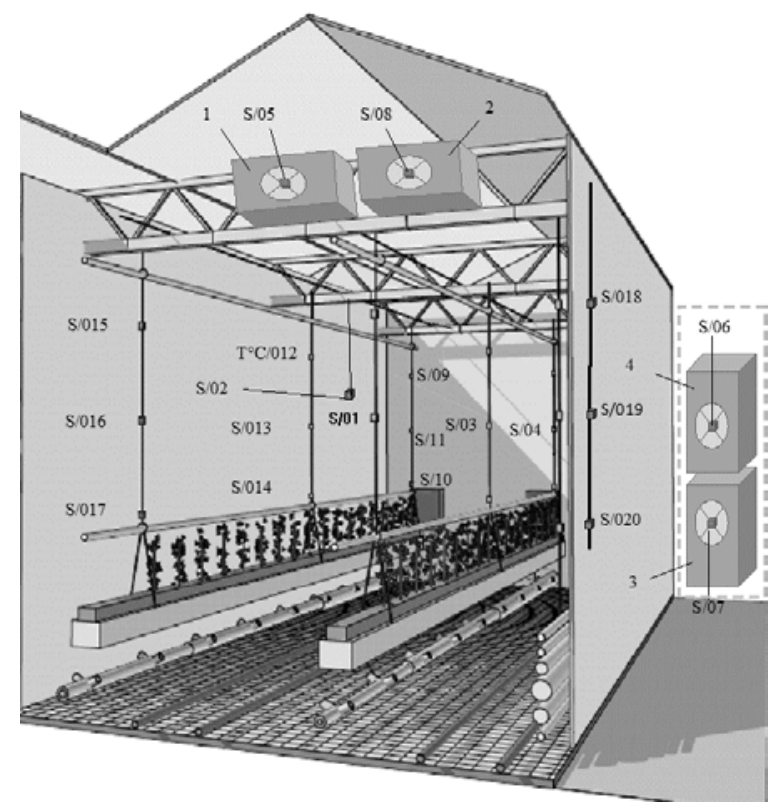

Fig. 1. Location of temperature sensors in the experimental greenhouse.

1., 2. heat pumps; 3., 4. heat pump outdoor unit; S/05, S/08 sensors exhaust air temperature of the heat pump; S/06; S/07 sensors exhaust air temperature of the heat pump outdoor unit; S/01-S/04; S/09-S/17 temperature sensors in the experimental greenhouse, $\mathrm{S} / 18-\mathrm{S} / 20$ sensors in the reference greenhouse.

The geographical location of the experiment was South East part of Latvia at latitude $56.5^{\circ} \mathrm{N}$ and longitude 25.8 ${ }^{\circ} \mathrm{E}$.

Two $5 \mathrm{~kW}$ heat Hitachi RAC-50 air to air reversible heat pumps were installed inside the greenhouse at a height of $1.8 \mathrm{~m}$ at the end wall and air was blown directly into the plant growing area. Water based pre-existing industrial heating system was disabled using heat insulators. Energy consumption of the heat pumps was measured by measuring the electrical power at the heat pump electricity connection. Reference greenhouse was heated using central heating by natural gas and the total amount of heating gas used was calculated from commercial data from the whole production facility. Assuming that the air temperature variables are irregularly distributed in the greenhouse, 18 temperature sensors with solar shields at different heights and positions were installed at 3 different heights and at 2x3 horizontal grid to measure the air temperature distribution in the experimental greenhouse and 4 sensors were used to measure the exhaust air temperatures of the heat pumps (Fig. 1). The control measurements were made at 3 different heights at the industrial facility heated by a common gas-water heating system.

Temperature spatial distribution measurement system was built to be conformed to the Linked Data nomination (Open, structured machine-readable, non-proprietary format, linked to other data, etc.). Data refer to known events at the time, spatial metadata (refer to OGC services), it is INSPIRE ready. For particular exploitation goals, data can be perceived as Real Time data. Layer for data storage was combined of database storage and file system. The main data storage was the relational database system PostgreSQL (further-DB). The spatial extension of the DB storage PostGIS was prepared for the storage of spatial data. There was a single data model planned and implemented, providing the following roles:

- storage of data produced by deployed temperature sensors;

- storage of data provided by possible other data sources/data producers (future development);

- management of data produced by stuff, activities, and other events (for future use);

- geodata - contextual spatial data related to greenhouses, its location, greenhouse and field species (future development).

Data management layer was based on components providing API for data exchange, analytical, processing and publishing functions. Specific open source application (feeder service) running on the server was created. This component was responsible for receiving sensor data from the defined sensor unit provider, processing the received data, and sending these data to the configured data storage(s) using HTTP API interface. MapServer was a component responsible for the publishing of contextual spatial data for visualization purposes. SensWEB as a web application based on Python framework was planned to provide the main functionality of the system. Initial deployment of the system provided a feeder service instance was prepared for gathering of sensor data from sensor node(s) and sending via defined API to SensWEB WEB server. SensWEB server instance consists of SensWEB web application and the provided data model implemented in the PostgreSQL DB with PostGIS spatial extension. Setup for online data gathering from sensor node(s) was installed. It allowed gathering data from the 
sensor units connected to a node named GreeNo over GSM connection in compressed format (Fig.2.).

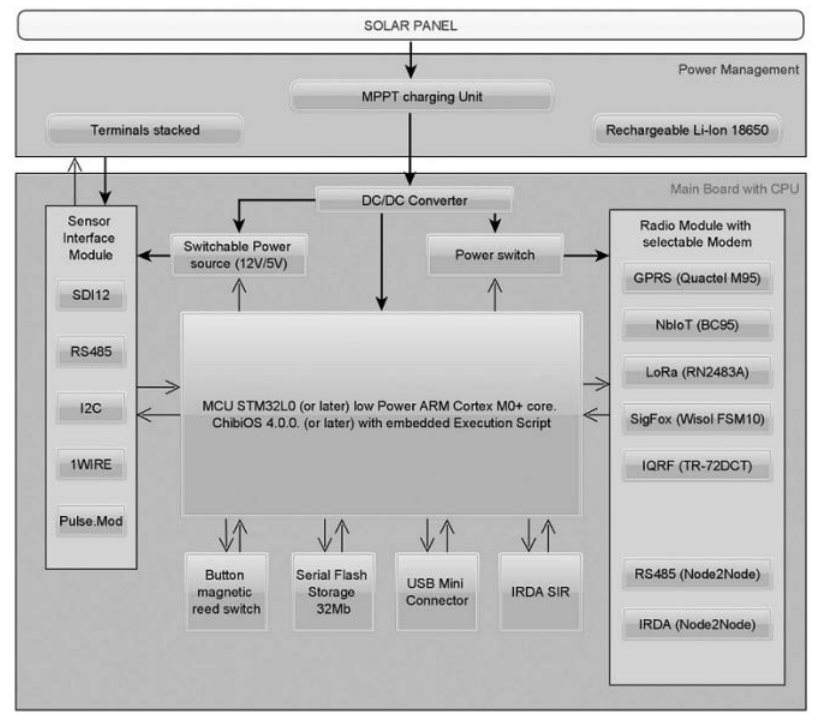

Fig. 2. Block schematics of GreeNo

The temperature sensing devices used a semiconductor thermometer based on chip DS18B20. Sensor units used for the research were specially constructed with explicitly exposed chips to the surrounding air (Fig. 3) providing faster measurement due to the lower connected mass resulting in lower thermal inertia. For data transport from GreeNo nodes to DB public GSM network GPRS and NBIoT services were used utilizing in GreeNo built-in GSM modem. For research and analysis needs interface for data export and download from the DB in format XLS, XLSX was used.

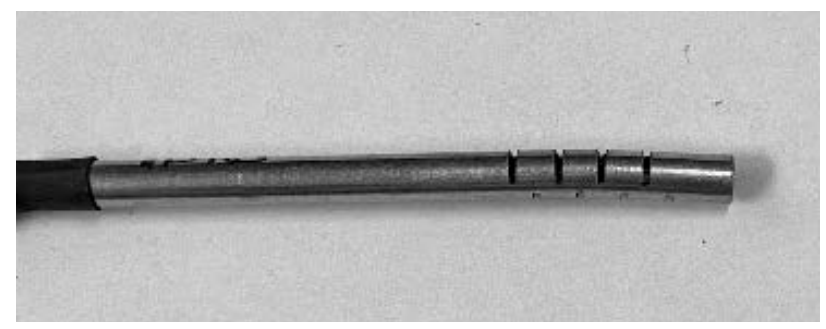

Fig. 3. Semiconductor thermometer based on DS18B20 chip.

Tomatoes were grown from the first decade of February until the end of October. Winter period of the growing season was warmer than usual. Outside average air temperatures over the whole season varied between $3.8^{\circ} \mathrm{C}$ and $24.1^{\circ} \mathrm{C}$ (Fig. 4.) In the experimental as well as reference greenhouse, the temperature had to be kept at 20$25{ }^{\circ} \mathrm{C}$ during the day and $12-15-18{ }^{\circ} \mathrm{C}$ during the night depending on the plant development stage and the time of the day.

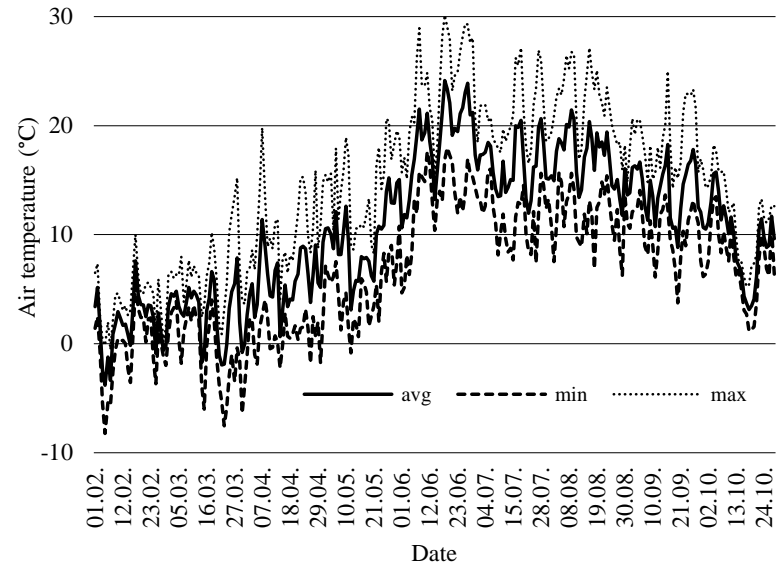

Fig. 4. Average, minimal and maximal day air temperature during vegetation 2020 .

Beef type tomato variety Admiro was grown in two rows with $1.2 \mathrm{~m}$ distance between the rows. At five to six leaf stage, the transplants were planted into bags filled with coconut fiber. A very shallow stream of water containing all dissolved nutrients required for tomato growth was recirculated past the roots of the plants in each row. The nutrient solution level was controlled by determining EC and $\mathrm{pH}$. Drop irrigation was incorporated into an industrial - reference greenhouse feeding system. Shading and ventilation were disconnected from the common system to test the cooling capacity of the heat pumps.

\section{RESULTS AND DISCUSSION}

Spatial uniformity of the temperature.

The spatial distribution of the temperature, measured as the temperature difference between temperature sensors at different positions in relation to the warm air exhaust of the heat pump was compared to the temperature in the reference greenhouse. For the control, the temperature difference between sensors at the highest and lowest positions was used as reference. In Fig. 5, both the temperature difference in the control and the temperature difference between the two pairs of sensors in the experimental greenhouse, where the highest difference was expected, are plotted against the temperature of the warm air at the heat pump exhaust. Temperature distribution plotted in Fig. 5 was measured in the period with the lowest outside temperatures during the 2020 season. Night between 23-rd and 24-th of March 2020 was the coldest night during the whole tomato growth season with outside temperatures between $-3{ }^{\circ} \mathrm{C}$ and $-7{ }^{\circ} \mathrm{C}$. The vertical temperature difference between the highest sensor at $1.8 \mathrm{~m}$ and the lowest at the height of $0.6 \mathrm{~m}$ in the experimental greenhouse was within $1.2^{\circ} \mathrm{C}$ measured at 7.3 meters from the heat pump exhaust. The horizontal temperature distribution in the experimental greenhouse was even more uniform - the temperature difference between the closest and the most remote temperature sensor with the distance of $6.8 \mathrm{~m}$ between them was for all measurements within $0.7^{\circ} \mathrm{C}$ and $90 \%$ of the measurements were within $0.5^{\circ} \mathrm{C}$. This should be compared with the control greenhouse with hot water central heating system where the vertical air 
temperature difference was within $1.2{ }^{\circ} \mathrm{C}$. Even during the coldest time when the heat pump was working with the highest capacity and with the highest hot air temperature, the spatial uniformity of the temperature in the experimental greenhouse heated by the heat pump was similar to the control greenhouse heated by a hot water central heating system.

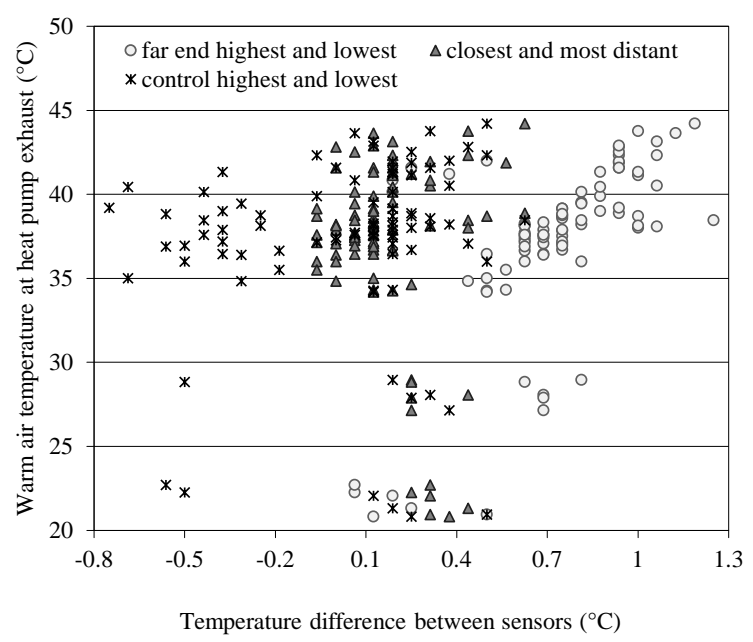

Fig. 5. Uniformity of the temperature inside the greenhouse during the period with the lowest outside temperature, ${ }^{\circ} \mathrm{C}$.

Temporal uniformity of the temperature.

Temporal uniformity of the temperature field during heating is one of the most important parameters for the air to air heat pump heating system. The installed air to air heat pumps do not operate in continuous heating mode. Hot air was blown into the greenhouse until the necessary temperature is achieved and then the heating is paused for some time and renewed again when the temperature is below a set limit. The built-in algorithm of the heat pump tries to smooth out these periods and achieve more continuous heating, but in practice there are periods with high and low warm air temperature at the heat pump heated air outlet. Typical heating air temperatures are from $35^{\circ} \mathrm{C}$ to $45{ }^{\circ} \mathrm{C}$. One of the concerns with direct heating of the greenhouse by air to air heat pumps is how the temperature of these on-off cycles is affecting the plants. In Fig. 6. the temperature measurements during one of the coldest nights are plotted against the time. Outside air temperature was between $-3{ }^{\circ} \mathrm{C}$ and $-7{ }^{\circ} \mathrm{C}$ and the heat pump was operating at its highest capacity during the whole experiment. Temperature variations inside the greenhouse caused by the on-off cycles were small - within $3^{\circ} \mathrm{C}$. On-off cycles of the heat pump are well visible in the plot. It can be speculated that the heat inertia of the sunshields around the temperature sensors moderated the temperature fluctuations caused by the heat pump switching on and off. Typical length of the heating cycle in Fig. 6. is approximately 40 minutes, which is sufficient for the temperature sensor to reach the thermal equilibrium with the air flow from the heat pump. By analyzing the temperature data, it was deemed that the temporal uniformity of the temperature is within $3{ }^{\circ} \mathrm{C}$ even during the coldest periods with the most intense heating was needed and that the fluctuations in the temperature are within the range acceptable for the plants.

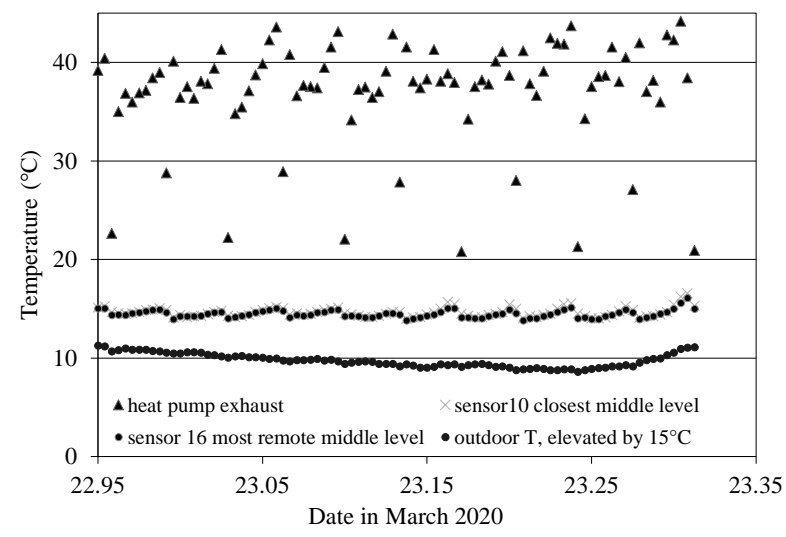

Fig. 6. The changes of air temperature in time ${ }^{\circ} \mathrm{C}$, the coolest night in March 2020.

The temporal uniformity of the temperature in the control greenhouse heated by the hot water central heating system showed slower temperature variation during the same period, but the overall temperature variation was also within $3{ }^{\circ} \mathrm{C}$ within one night.

Spatial temporal uniformity of the temperature field.

Changes in the temperature difference between sensors were studied for the time periods when the most intensive heating was required. In Fig. 7. the temperature differences between the high and low level sensors and the closest and the most remote sensors with respect to the hot air exhaust are plotted for one of the coldest nights in the year 2020 when the outdoor temperature dropped to $-7{ }^{\circ} \mathrm{C}$ during the night. In the control greenhouse, the vertical temperature difference between the highest and the lowest temperature sensors slowly drifted from $-0.5{ }^{\circ} \mathrm{C}$ to $0.5{ }^{\circ} \mathrm{C}$ during the night. This most probably was caused by the heat flow from the heating pipes at the bottom of the greenhouse and cooling via thermal radiation from the top of the greenhouse into the open sky.

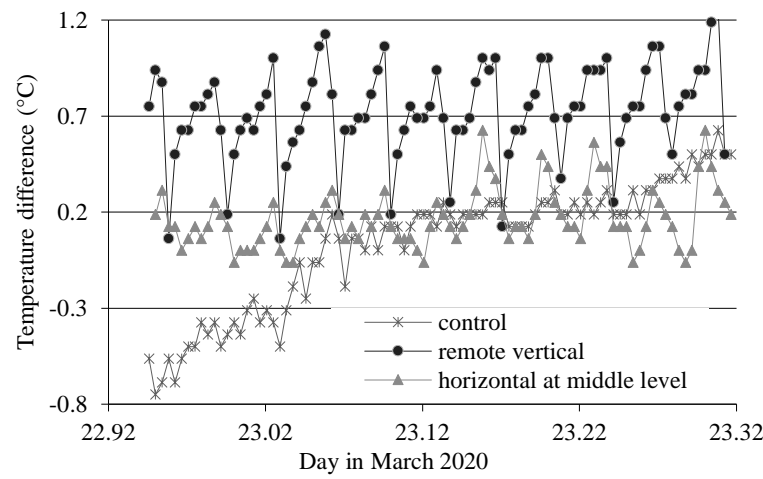

Fig. 7. Temperature difference between sensors plotted against the time during one of the coldest nights.

The vertical temperature difference between the highest and the lowest temperature sensors in the experimental greenhouse had periodic fluctuations from around $0{ }^{\circ} \mathrm{C}$ to $1{ }^{\circ} \mathrm{C}$ with the period of close to 1 hour that 
corresponds to the cycle of the heat pump activity that can be seen in Fig. 6. The time dependence of the temperature differences along the horizontal axis between the sensor closest to the hot air exhaust and the most remote one was measured to be smaller - temperature difference periodically fluctuated between $0{ }^{\circ} \mathrm{C}$ and $0.5^{\circ} \mathrm{C}$ in coherence with the heat pumps activity and increased slightly at the coldest time of the night till $0.6^{\circ} \mathrm{C}$ as can be seen comparing Fig. 6 and Fig. 7. The measurements showed that the spatial temporal variations of the temperature field in the experimental greenhouse were comparable to the control greenhouse with hot water central heating although the temperature differences fluctuated more frequently following the activity of the heat pump. The time-averaged temperature was more uniform in the experimental greenhouse compared to the reference. The air movement induced by the heat pump was sufficient to ensure equal heating even in most remote positions from the hot air exhaust. The periodic fluctuations of the temperature due to the changes in the heat pump activity were measured to be several times smaller than the temperature differences caused by changed intensity in insolation during the days when the sun was periodically shaded by clouds. In Fig. 8. the temperature difference between sensors is plotted over time at warm outdoor temperatures. Vertical temperature difference in the control greenhouse is represented by crosses, while the vertical temperature difference in the experimental greenhouse measured at the far end from the heat pump air exhaust and the horizontal temperature difference at the middle height are represented by open circles and triangles respectively.

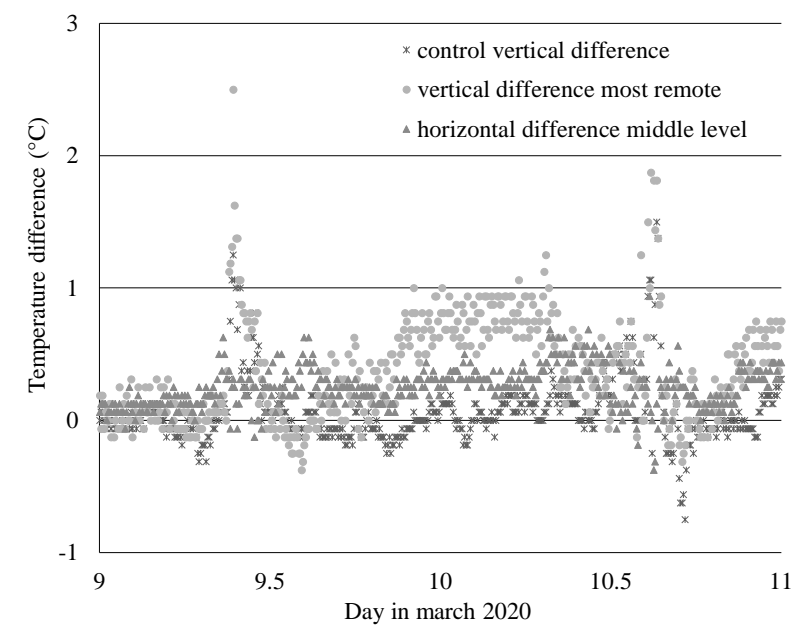

Fig. 8. Temperature difference between sensors at temperatures $1-8{ }^{\circ} \mathrm{C}$

Time dependent temperature differences between temperature sensors are shown in Fig. 6. Vertical temperature differences in the experimental greenhouse are higher in warm weather than in the coldest weather and reach $1{ }^{\circ} \mathrm{C}$ while in control there is a decrease in the vertical temperature differences. This can be explained by analyzing the heat pump hot air exhaust temperature shown in Fig. 9.

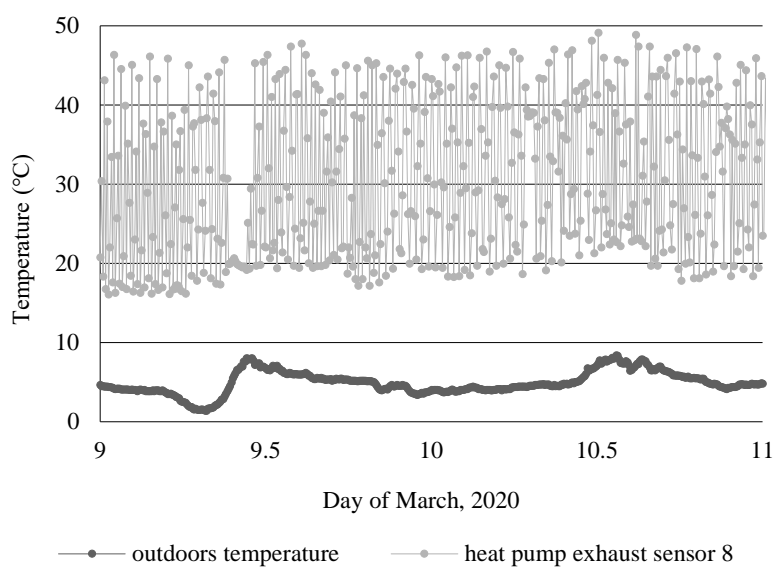

Fig. 9. Heating and outside air temperature fluctuation

The heat pump used in the experiment had the same maximum exhaust hot air temperature of $45^{\circ} \mathrm{C}$ working at warm outdoors temperatures as during the coldest time periods but increased the pause periods with low exhaust air temperature. The temperature fluctuations in the experimental greenhouse thus increased with increasing the outdoors temperature and decreasing the heating power. A different pattern is observed when solar radiation briefly eliminates the need for heating. A sharp rise of temperature differences up to $2.5{ }^{\circ} \mathrm{C}$ is observed in the vertical temperature distribution in the experimental greenhouse. In the reference greenhouse, the rise is smaller but is then followed by a dip of similar size in the reverse vertical temperature distribution, which is caused by heat inertia in the hot water heating system. It was established that the temperature uniformity during warm outdoor temperatures is still well within acceptable temperature variations.

Cooling with the heat pump.

During the summer, cooling with the heat pump was tested. The effect on plants was rather disastrous for the plants and productivity in the test facility. 23\% of plant stems died until the end of the season and the yield was $50 \%$ lower than in the control that was cooled with sunshields and by opening ventilation windows in the roof. One of the explanations can be the very low air temperatures coming out from the heat pump during the cooling cycle. As an example, the temperature data for one of the warmest days in July 2020. are shown in Fig. 10. Heat pump performed the most active cooling during evening time, because the set temperature regime is with lower temperature at night. Very low cold air exhaust temperatures, as low as $8{ }^{\circ} \mathrm{C}$ were observed during the evening hours that followed warm days. We estimate that these low cooling air temperatures injured plants and lowered their productivity. 


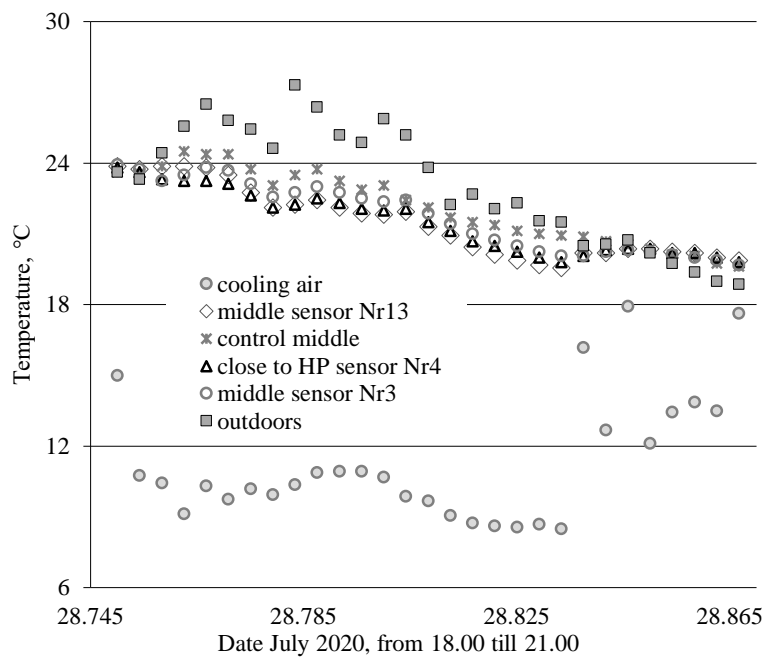

Fig. 10. Greenhouse air temperature in July, ${ }^{\circ} \mathrm{C}$

Energy efficiency and $\mathrm{CO}_{2}$ emissions.

It was estimated that the experimental facility had somewhat less solar irradiation because of its location, but these differences were not taken into account. For the overall heating season in 2020 the energy efficiency of the heat pump was approximately 8 times better compared to the reference heating in terms of energy use. In calculating the reduction of $\mathrm{CO}_{2}$ emissions, some assumptions have to be made for the $\mathrm{CO}_{2}$ emissions from the production of the electricity used for the heat pumps. Typical energy mix for Latvia electricity grid consists of gas powered cogeneration plants in big cities, coal thermal stations from Russia, nuclear energy from neighboring countries, hydropower from Latvia and Scandinavia, and a small part of other renewables. The proportion varies depending on the availability of different sources, but it can be assumed that approximately half of the electricity usually is from sources with low to zero $\mathrm{CO}_{2}$ emissions. Depending on the electricity production mode in the energy mix, the $\mathrm{CO}_{2}$ emissions in the experimental greenhouse were estimated to be 8-16 times smaller compared to the reference greenhouse heated by natural gas. Using market prices for electricity and natural gas, it was estimated that in 2020 heating season heating costs were somewhat smaller for the experimental greenhouse compared to reference heating expenses.

\section{CONCLUSIONS}

Spatial and temporal temperature differences in the experimental greenhouse heated by air-to-air heat pump were similar to the reference greenhouse with hot water central heating. Colling with direct air flow from air-to-air heat pump was injuring for tomato plants and decreased the productivity significantly. Use of air-to air heat pumps demonstrated 8 to 16 fold reduction in $\mathrm{CO}_{2}$ emissions when compared to heating by natural gas while there was no increase in heating costs.

\section{Acknowledgments:}

This research was funded by European Regional Development Fund (ERDF) 2014-2020 for Operational Groups: 16.2. Support for the development of new products, methods, processes, and technologies. Project Nr. 17-00-A01620-000013.

\section{REFERENCES}

[1] M. Canakci, N. Yasemin Emekli, S. Bilgin, N. Caglayan, "Heating requirement and its costs in greenhouse structures: A case study for Mediterranean region of Turkey”, Renewable and Sustainable Energy Reviews, vol. 24., , pp. 483-490, 2013.

[2] L. Zhang, X. Hao, Y. Li, G. Jiang, "Response of greenhouse tomato to varied low pre-night temperatures at the same daily integrated temperature,” Hortiscience, vol. 45 (11), pp. 1654 1661, 2010.

[3] IPCC. Climate Change 2014: Mitigation of Climate Change. Contribution of Working Group III to the Fifth Assessment Report of the Intergovernmental Panel on Climate Change [Edenhofer, O., R. Pichs-Madruga, Y. Sokona, E. Farahani, S. Kadner, K. Seyboth, A. Adler, I. Baum, S. Brunner, P. Eickemeier, B. Kriemann, J. Savolainen, S. Schlömer, C. von Stechow, T. Zwickel and J.C. Minx (eds.)]. Cambridge University Press, Cambridge, United Kingdom and New York, NY, USA, 2014.

[4] Y. Tong a, T. Kozai, N. Nishioka, K. Ohyama, “Greenhouse heating using heat pumps with a high coefficient of performance (COP),” Biosystem Engineering, vol. 106., pp. 405 - 411, 2010.

[5] T. Kozai, K. Ohyama, Y. Tong, P. Tongbai, N. Nishioka, "Integrative environmental control using heat pumps for reductions in energy consumption and $\mathrm{CO}_{2}$ gas emission, humidity control and air circulation,” Scientia Horticulturae, vol. 893, pp. 445-449, 2011.

[6] R. S Atlason, G. V. Oddsson, R. Unnthorsson, "Heat pumps in subarctic areas: current status and benefits of use in Iceland,” Int $\mathrm{J}$ Energy Environ Eng., vol. 8, pp. 283-291, 2017. Available: SprigerLink, https://link.springer.com/article/10.1007/s40095017-0244-6 [Accessed February 26, 2021], https://doi.org/10.1007/s40095-017-0244-6

[7] A. Grubbauer, J. Flucha, C. Brunnera, T. Ramschaka, V. Wilkb, T. Flecklb, "Renewable and highly efficient energy systems through innovative combination of solar thermal and heat pump systems," Chemical engineering transactions, vol. 70, pp. 745750, 2018.

[8] M. K. Mattinen, A. Nissinen, S. Hyysalo, J. K. Juntunen, “Energy use and greenhouse gas emissions of air-source heat pump and innovative ground-source air heat pump in a cold climate," Journal of Industrial Ecology, vol. 19(1), pp. 61-70. 2014. Aviable: Wiley Online Library, https://onlinelibrary.wiley.com/doi/abs/10.1111/jiec.12166 [Accessed March 8, 2021], https://doi.org/10.1111/jiec.12166

[9] D. P. Rubanga, K. Hatanaka, S. Shimada, "Development of a simplified smart agriculture system for small-scale greenhouse farming, " Sensors and Materials, vol. 31, No. 3, pp. 831-843, 2019. 